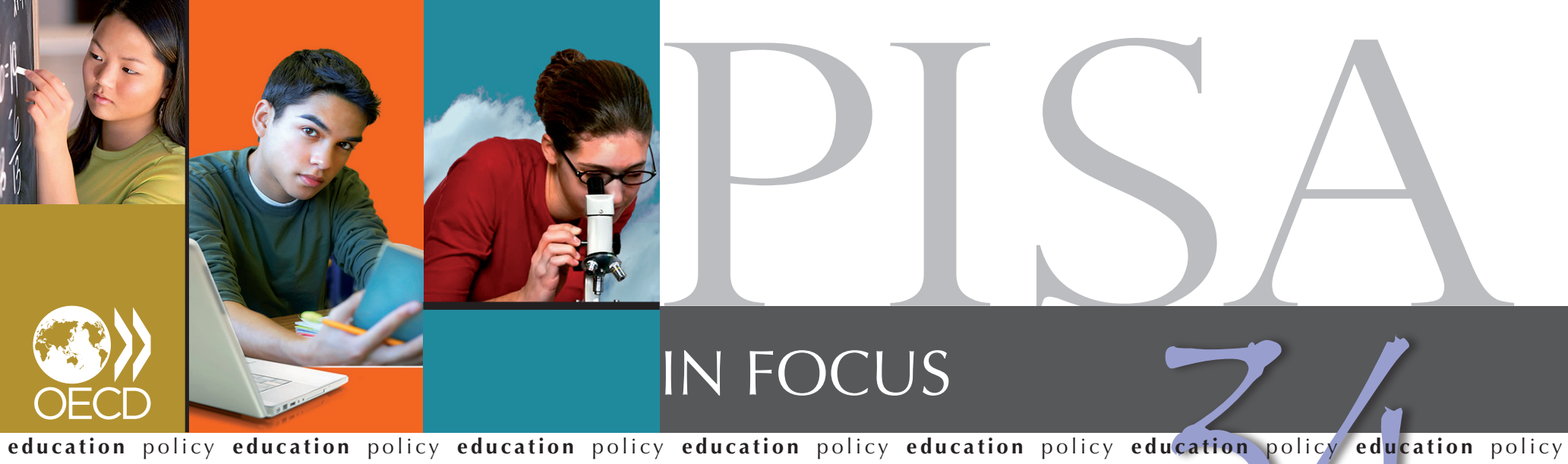

\title{
Who are the strong performers and successful reformers in education?
}

- Strong performers and successful reformers in education share some key characteristics: a belief in the potential of all their students, strong political will, and the capacity of all stakeholders to make sustained and concerted efforts towards improvement.

- Countries/Economies that have improved their reading performance over the years have done so by reducing the proportion of poor-performing students, increasing the share of high performers, and/or weakening the impact of students' socio-economic status on their performance.

The release of PISA results invariably prompts lively discussion about education policy within participating countries and economies. Why should we care about the findings from this triennial assessment of the success of education systems in preparing their students for a full, productive life? PISA is not just a snapshot of 15-year-olds' performance in reading, mathematics and science at a particular point in time; it is also a glimpse into the future. The recent Survey of Adult Skills, a product of the OECD Programme for the International Assessment of Adult Competencies (PIAAC), finds a close correlation between countries' performance in the different cycles of PISA and the proficiency of the corresponding age groups in literacy and numeracy later on in life. Results from the adult survey also show that highly skilled adults are twice as likely to be employed and almost three times more likely to earn an above-median salary than poorly skilled adults. In other words, poor skills severely limit people's access to better-paying and more rewarding jobs. Highly skilled people are also more likely to volunteer, see themselves as actors rather than as objects of political processes, and are more likely to trust others. Fairness, integrity and inclusiveness in public policy thus all hinge on the skills of citizens. 


\section{PISA measures success in education...}

Many of these skills are acquired during compulsory education. PISA doesn't only measure what students near the end of compulsory education know, it measures what they can do with what they know. Equally important, by comparing student performance and factors related to performance, such as students' attitudes towards learning, their socio-economic background, and education policies, practices and resources across participating countries and economies, PISA offers policy makers and educators a way to identify the world's most effective education policies that they can then adapt to their local contexts.
Over the years PISA has illustrated that strong performers in education - such as Canada, Finland, Hong Kong-China, Japan, Korea, New Zealand and Shanghai-China - are found in a variety of regions, have diverse cultural traditions and are at various stages of development. PISA results also show that strong performance does not have to be achieved at the expense of equity in education: in some high-performing countries, socio-economically disadvantaged students perform just as well as advantaged students. For example, Canada, Estonia, Finland, Hong Kong-China, Iceland, Korea and Liechtenstein all show above-average performance in reading and are places where socio-economic status has less impact on performance than it does in other countries.

\section{Equity and high performance are not mutually exclusive}

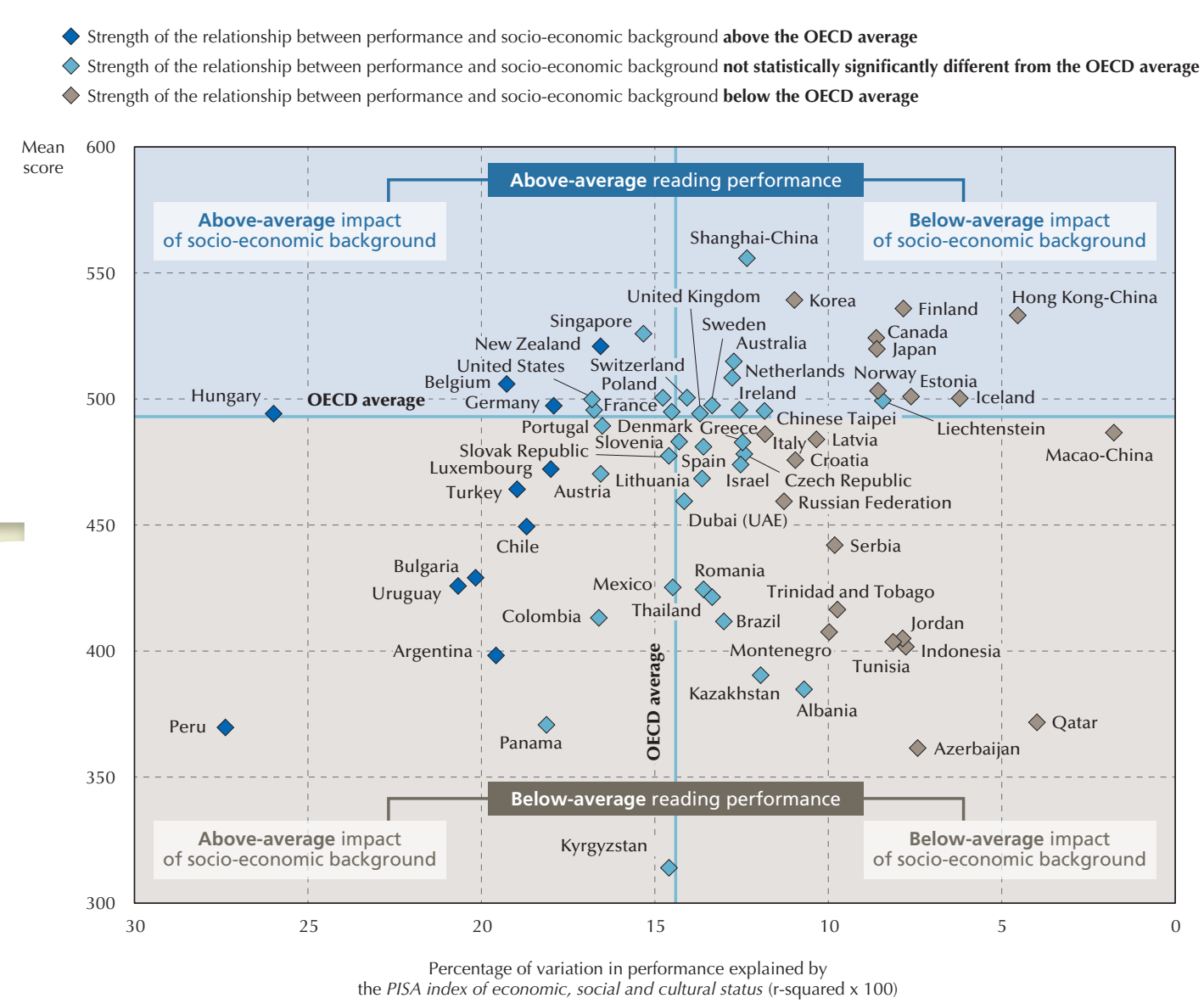

Source: OECD PISA 2009 database, Table II.3.2.

StatLink तiा Th http://dx.doi.org/10.1787/888932343589 

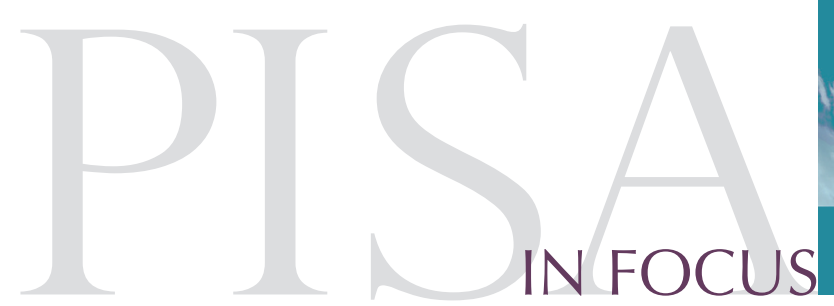

\section{... and shows how countries and economies can improve their education systems.}

Now that PISA is more than ten years old, it can also show the evolution of student performance over time. In 2009 PISA identified a set of countries that could be considered successful reformers - countries where 15-year-olds at the end of the first decade of the new millennium were more proficient in reading than their counterparts were in 2000. Of the 26 countries with comparable information, half - namely Albania, Brazil, Chile, Germany, Hungary, Indonesia, Israel, Korea, Latvia, Liechtenstein, Peru, Poland and Portugal - improved in reading between 2000 and 2009. The fact that such a diverse group of countries succeeded in raising the level of their students' performance in reading is a further indication that any country can improve, irrespective of its culture, traditions, level of development or initial level of skills.

Countries such as Brazil, Indonesia and Peru improved to the extent that their reading scores rose from far below average in 2000 to much closer to the average in 2009. These countries significantly reduced the share of students with poor reading proficiency. Other countries, such as Japan and Korea, built on their already high performance by increasing the proportion of students who achieve at the highest levels. In Albania, Chile, Germany and Latvia, countries that were at different levels of performance initially, the relationship between students' socio-economic status and their reading performance weakened and students' overall reading performance improved.

These examples show that students' proficiency in reading, mathematics and science is neither pre-determined nor fixed; all students can improve in the right conditions. PISA helps to identify those conditions: the specific practices and policies that provide more effective learning opportunities for students.

\section{Improving education systems is a shared - and high-stakes - responsibility.}

But PISA also shows that around half of the countries with comparable information saw no improvement in student performance between 2000 and 2009. Taken together, these results underscore the fact that improvements in education require political will, sustained and concerted efforts, and shared responsibility among policy makers, educators, individual students and their families.

PISA also tries to capture students' ability to adapt to rapidly changing environments through its own innovations. In 2009, for example, PISA tested students on their digital reading skills, examining how prepared 15-year-olds are to navigate through on-line material and use information acquired digitally.

Poor performance in PISA can signal difficulties later on

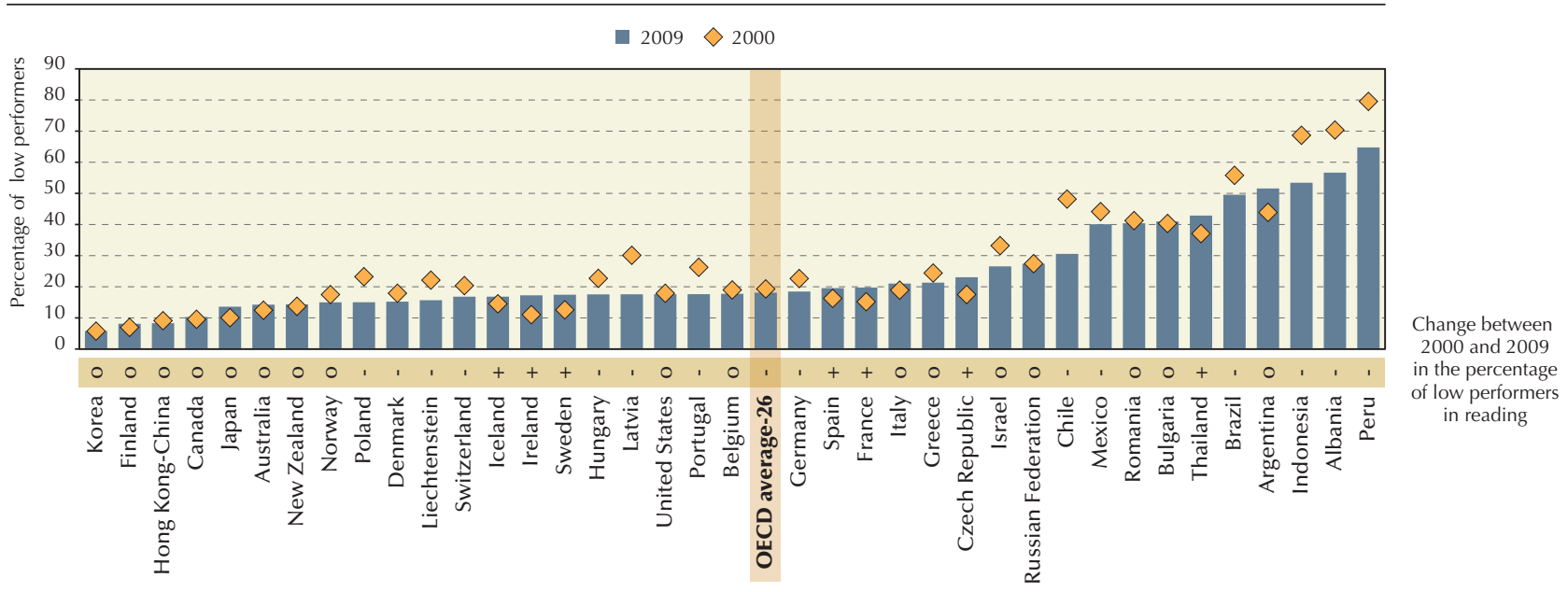

Note: Countries are ranked in ascending order of the percentage of low performers (students below proficiency Level 2) in reading in 2009 .

Source: OECD PISA 2009 database, Table V.2.2.

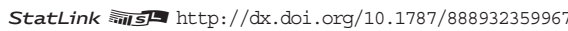

\begin{tabular}{|c|c|c|c|}
\cline { 2 - 4 } \multicolumn{1}{c|}{} & $\begin{array}{c}\text { 2009 higher } \\
\text { than } 2000\end{array}$ & $\begin{array}{c}2009 \text { lower } \\
\text { than } 2000\end{array}$ & $\begin{array}{c}\text { No statistically } \\
\text { significant difference }\end{array}$ \\
\hline $95 \%$ confidence level & + & - & 0 \\
\hline
\end{tabular}


As 15-year-olds are increasingly asked to use computers in their daily lives, in 2012, the digital reading assessment was complemented by a digital mathematics assessment and, for the first time, an assessment of how well students can solve complex problems set in a digital environment. PISA also responded to the questions raised in the wake of the financial crisis of 2008 by developing a comparative assessment of students' financial literacy to understand whether 15-year-olds understand financial concepts and can use financial information to make informed decisions.

So if you ask why you should care about PISA results, consider your child's future, your own performance in school or at work, and your country's ability to compete in a globalised economy. That's why you should care.

The source of a country's talent pool is its top performers

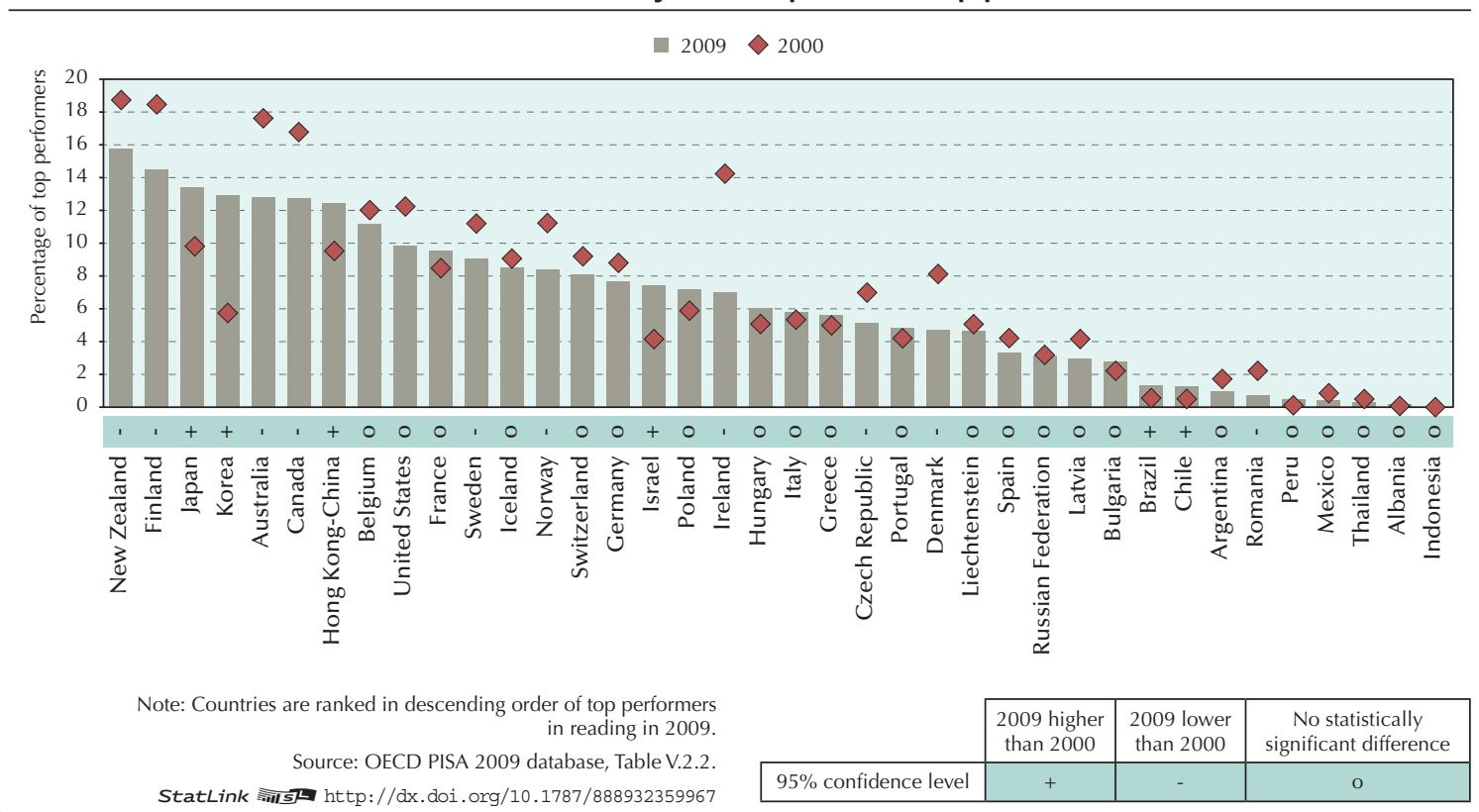

The bottom line: All students, everywhere, can be high achievers and/or improve their performance. PISA results not only reveal what is possible, they also underscore the importance of political will, sustained and concerted efforts, and shared responsibility among all stakeholders in achieving excellence in education.

For more information

Contact Andreas Schleicher (Andreas.Schleicher@oecd.org)

See OECD (2010), PISA 2009 Results: What Students Know and Can Do: Student Performance in Reading, Mathematics and Science, Volume I, OECD Publishing;

OECD (2010), PISA 2009 Results: What Makes a School Successful? Resources, Policies and Practices, Volume IV, OECD Publishing.

Visit

www.pisa.oecd.org

www.oecd.org/pisa/infocus
Coming next month

Key results from PISA 2012 